\title{
Conversion of Sago (Metroxylon sagu) Pith Waste to Fermentable Sugars via a Facile Depolymerization Process
}

\author{
Suh Cem Pang ${ }^{1}$ (D) Lee Ken Voon ${ }^{1} \cdot$ Suk Fun Chin ${ }^{1}$
}

Received: 4 July 2017 / Accepted: 22 September 2017 /

Published online: 30 September 2017

(C) Springer Science+Business Media, LLC 2017

\begin{abstract}
The conversion of starchy sago (Metroxylon sagu) pith waste (SPW), a lignocellulosic biomass waste, to fermentable sugars under mild conditions had been successfully demonstrated. The optimum depolymerization of SPW was achieved at $2 \mathrm{wt} \%$ sample loading which was catalyzed by $100 \mathrm{mM}$ of oxalic acid in the presence of $25 \mathrm{wt} \% \mathrm{NaCl}$ solution at $110{ }^{\circ} \mathrm{C}$ for $3 \mathrm{~h}$. Up to $97 \%$ SPW sample was being converted into fermentable sugars with limited formation of by-products after two sequential depolymerization cycles. Both reaction temperature and concentration of oxalic acid were crucial parameters for the depolymerization of SPW which exhibited a high selectivity for the production of glucose over other reducing sugars.
\end{abstract}

Keywords Depolymerization · Inorganic salt · Dicarboxylic acid · Lignocellulosic biomass

\section{Introduction}

Lignocellulosic biomass wastes in the form of agricultural residues, forestry, and industrial wood wastes are abundant and renewable natural resources which contain major constituents of cellulose, hemicellulose, and lignin [1]. Therefore, conversion of lignocellulosic biomass wastes into useful products could alleviate many socio-economic problems including depletion of fossil fuels and environment pollution [2]. In recent years, there were numerous studies on the utilization of lignocellulosic biomass wastes as the precursor materials for the production of value-added products such as enzymes, fermentable sugars, and biofuels [3-5].

Sago pith waste (SPW) is a fibrous starchy lignocellulosic side product of sago starch extraction from the pith of sago palm (Metroxylon sagu) [6]. In Malaysia, the state of Sarawak

Suh Cem Pang

scpang@unimas.my; suhcem@gmail.com

1 Faculty of Resource Science and Technology, Universiti Malaysia Sarawak, 94300 Kota Samarahan, Sarawak, Malaysia 
has been recognized as one of the largest sago starch exporters in the world with daily generation of 10 tons of SPW from sago starch processing factories [7]. The SPW was normally being drained into nearby rivers together with sago effluent without proper treatment, thus leading to serious environmental problems.

Untreated SPW contains about $60 \mathrm{wt} \%$ starch, $23 \mathrm{wt} \%$ cellulose, $9 \mathrm{wt} \%$ hemicellulose, and $4 \mathrm{wt} \%$ lignin on dry weight basis which can be used as a favorable starchy lignocellulosic feedstock for sugar production [8]. The production of sugar from lignocellulosic biomass involves two important processes which are pretreatment and hydrolysis or depolymerization [9]. In the past decade, various types of pretreatment such as physical, chemical, physicochemical, and biological processes have been developed to alter the recalcitrance structural characteristics of lignocellulosic biomass $[10,11]$. Depolymerization is an essential stage for the conversion of SPW to fermentable sugars which are then converted to ethanol by microbial fermentation.

Currently, acid and enzymatic hydrolysis are widely applied to cleave the glycosidic bonds in starch and cellulose into fermentable sugars [12]. Nevertheless, these existing approaches tend to have high production cost due to expensive price of enzyme, time-consuming process (minimum $24 \mathrm{~h}$ of reaction time) and low tolerant to reaction condition and require high dilution that gives low yield of sugars [13, 14]. Besides, hydrothermal hydrolysis had also been employed to produce sugar [15]. However, this hydrothermal depolymerization process requires to be conducted at $310{ }^{\circ} \mathrm{C}$ and $9.8 \mathrm{MPa}$ which are very costly to achieve on an industrial scale $[16,17]$. Therefore, the use of energy-efficient, economic, and time-effective processes for the conversion of starch, cellulose, and hemicellulose into fermentable sugar is of the greatest concern for commercial biofuel production.

Inorganic salts are usually being used in strong inorganic acid catalysis in aqueous media to enhance swelling or even dissolution of the substrate slurry, thus increasing the breakdown of lignocellulosic biomass by mineral acids $[18,19]$. It is believed that ions of inorganic salt perform action analogous to ionic liquid by interacting via extensive hydrogen bonding of lignocellulosic biomass and further cleavage of hydrogen bond networks [20].

Organic acid such as dicarboxylic acids have low $p K a$ values and more environmental friendly than conventional mineral acids such as sulphuric acid and hydrochloric acid. They can be used as catalysts for the depolymerization of lignocellulosic biomass [21, 22]. The use of fumaric acid, oxalic acid, or maleic acid in the hydrolysis of lignocellulosic biomass had shown lesser degradation of sugar as compared to mineral acids [23-25].

Herein, we have reported the use of a facile depolymerization method for the conversion of SPW into fermentable sugar in the presence of inorganic salt and dicarboxylic acid and under mild condition. The depolymerization process was optimized by varying the type of salt and concentration, catalyst loading, temperature and amount of biomass substrate as well as cycle of depolymerization in order to obtain the highest yield of fermentable sugars.

\section{Materials and Methods}

\section{Materials}

Sago (Metroxylon sagu) pith waste (SPW) was collected from local sago starch processing factories in Sarawak, Malaysia. Sodium hydroxide $(\mathrm{NaOH})$, lithium chloride $(\mathrm{LiCl})$, and citric acid were purchased from Merck (American Pharmaceutical Company) whereas oxalic acid, 
succinic acid, maleic acid, ammonium chloride $\left(\mathrm{NH}_{4} \mathrm{Cl}\right)$, zinc chloride $\left(\mathrm{ZnCl}_{2}\right), \mathrm{D}$-glucose, and 3,5-dinitrosalicyclic acid were purchased from Sigma-Aldrich (Darmstadt, Germany). Both calcium chloride $\left(\mathrm{CaCl}_{2}\right)$ and potassium chloride $(\mathrm{KCl})$ were purchased from JT Baker. All chemicals were used without further purification.

\section{Methods}

\section{Characterization of SPW}

Samples of SPW were dried to constant weight under direct sunlight and were then ground and sieved through a 20-mesh sieve. The chemical composition of SPW such as starch, cellulose, hemicellulose, and lignin was analyzed by using standard procedures adopted from the National Renewable Energy Laboratory, USA (NREL), Chemical Analysis and Testing Laboratory Analytical Procedures 42624 [26] and 42618 [27]. For determining starch content in SPW, $0.1 \mathrm{~g}$ of sample was dispersed in $2 \mathrm{~mL} 2 \mathrm{M}$ of KOH and then reacted with $8 \mathrm{~mL} 1.2 \mathrm{M}$ sodium acetate buffer $(\mathrm{pH} 3.8)$ together with $0.1 \mathrm{~mL}$ of thermostable $\alpha$-amylase and $0.1 \mathrm{~mL}$ of amyloglucosidase in a water bath at $50{ }^{\circ} \mathrm{C}$. The dispersion was incubated for $30 \mathrm{~min}$. The sample was filtered and the liquid aliquot was diluted with deionized water in the factor of 1 to 10. The diluted liquid aliquot $(0.1 \mathrm{~mL})$ was then added into a test tube containing $3 \mathrm{~mL}$ of glucose oxidase peroxidase (GOPOD) reagent and incubated at $50{ }^{\circ} \mathrm{C}$ for $20 \mathrm{~min}$. The absorbance of the sample and D-glucose standard against the reagent blank were measured at the wavelength of $510 \mathrm{~nm}$ using a UV-Vis spectrophotometer (Shimadzu Model UV-160A). The weight percentage of starch content was determined using Eq. (1).

$$
\text { Starch Content }(\mathrm{wt} \%)=\frac{\text { Absorbance of } \quad \text { sample }}{\text { Absorbance of } \mathrm{D}-\text { glucose } \quad \text { standard }(100 \mu \mathrm{g})} \times 100 \times 0.9
$$

For determining the cellulose, hemicellulose and lignin contents, the destarched SPW sample $(0.3 \mathrm{~g})$ was hydrolyzed in $3 \mathrm{~mL}$ concentrated sulfuric acid $(72 \%)$ for $1 \mathrm{~h}$ then the acid was diluted to $4 \%$ concentration by adding deionized water $(84 \mathrm{~mL})$. The diluted sample was filtered by vacuum filter. Cellulose and hemicellulose content in destarched SPW sample can be determined by measuring sugar monomer (glucose and arabinose) concentrations in the liquid hydrolysate by using high-performance liquid chromatography (HPLC) (Shimadzu Model LC-20A). The weight percentage of cellulose, and hemicellulose was calculated based on Eq. (2).

$$
\begin{aligned}
& \text { Concentration of sugar monomer }(\mathrm{wt} \%) \\
& =\frac{\mathrm{C} \times \text { anhydro } \text { correction } \times 87.0}{\text { weight of destarched } \mathrm{SPW}} \times 100
\end{aligned}
$$

where concentration of sugar monomer in the hydrolyzed sample after correction for loss on $4 \%$ hydrolysis and anhydro correction is the correction factor used to convert the concentration of corresponding monomer sugar to polymeric sugar ( 0.88 for arabinose and 0.9 for glucose).

The acid soluble lignin was determined through measuring liquid hydrolysate obtained from acid hydrolysis of destarched SPW by using UV-Vis Spectrophotometer (Shimadzu Model UV-160A) at a wavelength of $236 \mathrm{~nm}$. The acid insoluble lignin was determined by ashing the acid insoluble residue at $575{ }^{\circ} \mathrm{C}$ in a furnace (Elite BCF11/8). The weight percentages of acid soluble lignin and acid insoluble lignin were calculated based on Eqs. 
(3) and (4), respectively. The total lignin content was then calculated from the sum of acid soluble and insoluble lignin. All analyses for the characterization of SPW samples were performed in triplicates.

$$
\text { Acid Insoluble Lignin }(\mathrm{wt} \%)=\frac{\text { Weight of destarch SPW-Weight of ash }}{\text { weight of destarched SPW }} \times 100
$$

$$
\text { Acid Soluble Lignin }(\mathrm{wt} \%)=\frac{\text { Absorbance } \times 87.0 \times \text { dilution }}{30 \times \text { weight of destarched } \mathrm{SPW}} \times 100
$$

\section{Depolymerization of SPW}

The SPW sample $(0.5 \mathrm{~g})$ was dispersed in a solution mixture containing different types of salt and dicarboxylic acid in a $100-\mathrm{mL}$ glass bottle (Duran Schott). The dispersion was magnetically stirred for $10 \mathrm{~min}$ at room temperature and then heated to the desired reaction temperature for the predetermined durations. The effects of different depolymerization conditions such as amount of sample (0.5-8.0 wt\%), type of salt $\left(\mathrm{NaCl}, \mathrm{LiCl}, \mathrm{KCl}, \mathrm{NH}_{4} \mathrm{Cl}, \mathrm{ZnCl}_{2}\right.$, $\mathrm{CaCl}_{2}$ ), concentration of salt (5-35 wt \%), type of dicarboxylic acid (oxalic acid, maleic acid, citric acid, succinic acid), concentration of dicarboxylic acid (10-400 mM), reaction temperature $\left(75-170{ }^{\circ} \mathrm{C}\right)$, and reaction cycles $(1-4$ cycles) as well as reaction time $(1-9 \mathrm{~h})$ on the yields of total reducing sugar were studied. All analyses were performed in triplicates.

\section{Determination of Total Reducing Sugar}

The total reducing sugar (TRS) concentration of depolymerization products was determined by the 3,5-dinitrosalicylic acid (DNS) assay [28]. Typically, a filtered depolymerized sample solution $(1 \mathrm{~mL})$ was placed in a test tube and then DNS reagent $(2 \mathrm{~mL})$ was added. The mixture solution was stirred for $1 \mathrm{~min}$ and heated in a boiling water bath for 5-10 min to ensure all reducing groups had bound to DNS to form DNS conjugates. The resulting solution was cooled to room temperature and diluted with deionized water by a factor of 10 . The absorbance of the reducing sugar was measured at the wavelength of $540 \mathrm{~nm}$ using a UV-Vis spectrophotometer (Shimadzu Model UV-160A). The concentration of TRS was then calculated from a standard glucose absorption calibration curve. All analyses were performed in triplicates and mean value and standard deviation were determined. The TRS yield of SPW sample was determined based on Eq. (5).

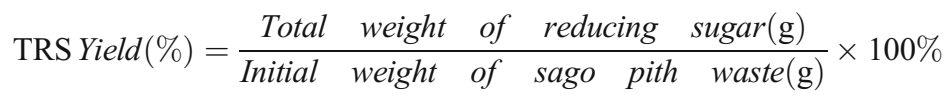

\section{High-Performance Liquid Chromatography Analysis}

HPLC analysis was performed to quantify the concentration of TRS. The sample solutions were filtered using $0.45-\mu \mathrm{m}$ membrane filter discs and were analyzed using HPLC (Shimazu Model LC-20A) equipped with a Bio-Rad Aminex HPX-871 $(100 \times 7.8 \mathrm{~mm})$ column and a refractive index detector. An aqueous solution of sulfuric acid $(5 \mathrm{mM})$ was used as the mobile 
phase. The samples were analyzed in isocratic mode at a flow rate of $0.8 \mathrm{~mL} \mathrm{~min}^{-1}$ at $65{ }^{\circ} \mathrm{C}$ and $20 \mu \mathrm{L}$ injection volume. The detected compounds were identified by comparison of retention times with those of corresponding commercial reference compounds (glucose, xylose, cellobiose, arabinose). Calibration graph of the HPLC was carried out with standard D-glucose. All analyses were performed in triplicates and mean value and standard deviation were determined.

\section{Results and Discussion}

\section{Sample Composition Analysis}

The major components of SPW sample were consisted of starch $(56.0 \pm 2.0 \mathrm{wt} \%)$, cellulose $(22.6 \pm 1.0 \mathrm{wt} \%)$ and hemicellulose $(7.80 \pm 1.5 \mathrm{wt} \%)$, and lignin $(5.50 \pm 1.4 \mathrm{wt} \%)$ which were comparable with findings reported by Vincent et al. [29]. The SPW was chosen as the prime feedstock material for the production of fermentable sugars since about 80 wt $\%$ of SPW consisted of starch and cellulose components.

\section{Depolymerization of SPW}

The SPW was depolymerized in different inorganic salt solutions (10 wt $\%)$ and catalyzed by $100 \mathrm{mM}$ of oxalic acid (Fig. 1a). With the exception of $\mathrm{NH}_{4} \mathrm{Cl}$ and $\mathrm{ZnCl}_{2}$, addition of inorganic salts resulted in higher yields of TRS as compared to that of pure water. In particular, the addition of $\mathrm{NaCl}, \mathrm{LiCl}$, and $\mathrm{CaCl}_{2}$ was observed to substantially enhance the efficiency of SPW depolymerization, with yields of TRS more than two times higher than that of pure water. In consideration of cost and availability, the choice of $\mathrm{NaCl}$ in combination with oxalic acid appears to be the most favorable for the depolymerization of SPW under mild conditions.

The effect of $\mathrm{NaCl}$ concentration within the range of 0 to $35 \mathrm{wt} \%$ on the yield of TRS produced was shown in Fig. 1b. In absence of $\mathrm{NaCl}$, the depolymerization of SPW was close to zero at $100{ }^{\circ} \mathrm{C}$ up to $2 \mathrm{~h}$ and only $0.8 \mathrm{~g} / \mathrm{L}$ of TRS was produced after $6 \mathrm{~h}$. However, upon addition of $\mathrm{NaCl}$, the depolymerization rate of SPW was enhanced substantially (Fig. 1b). The TRS produced with addition of 5 and $15 \mathrm{wt} \%$ of $\mathrm{NaCl}$ were 1.97 and $4.00 \mathrm{~g} / \mathrm{L}$, respectively, at the reaction time of $6 \mathrm{~h}$. The addition of 25 and $35 \mathrm{wt} \%$ of $\mathrm{NaCl}$ was observed to give the highest rate of depolymerization of SPW and produced more than eight times higher TRS concentration $(6.42$ and $6.66 \mathrm{~g} / \mathrm{L})$ than that of pure water $(0.80 \mathrm{~g} / \mathrm{L})$. Twenty-five weight percent $\mathrm{NaCl}$ solution was used for subsequent investigations on the depolymerization of SPW since TRS concentration produced was quite similar to that of $35 \mathrm{wt} \% \mathrm{NaCl}$ solution. In addition, the solubility of $35 \mathrm{wt} \% \mathrm{NaCl}$ solution decreased in the presence of oxalic acid in the solution.

\section{Effect of Dicarboxylic Acid}

One hundred millimolar of different types of dicarboxylic acids (oxalic acid, maleic acid, citric acid, and succinic acid) was used to study their catalytic activity in the depolymerization of SPW (Fig. 2a). TRS concentration after depolymerization for $6 \mathrm{~h}$ was observed to increase in the order of succinic acid < citric acid < maleic acid < oxalic acid. Except for succinic acid, the addition of dicarboxylic acid was observed to substantially enhance the depolymerization rates 

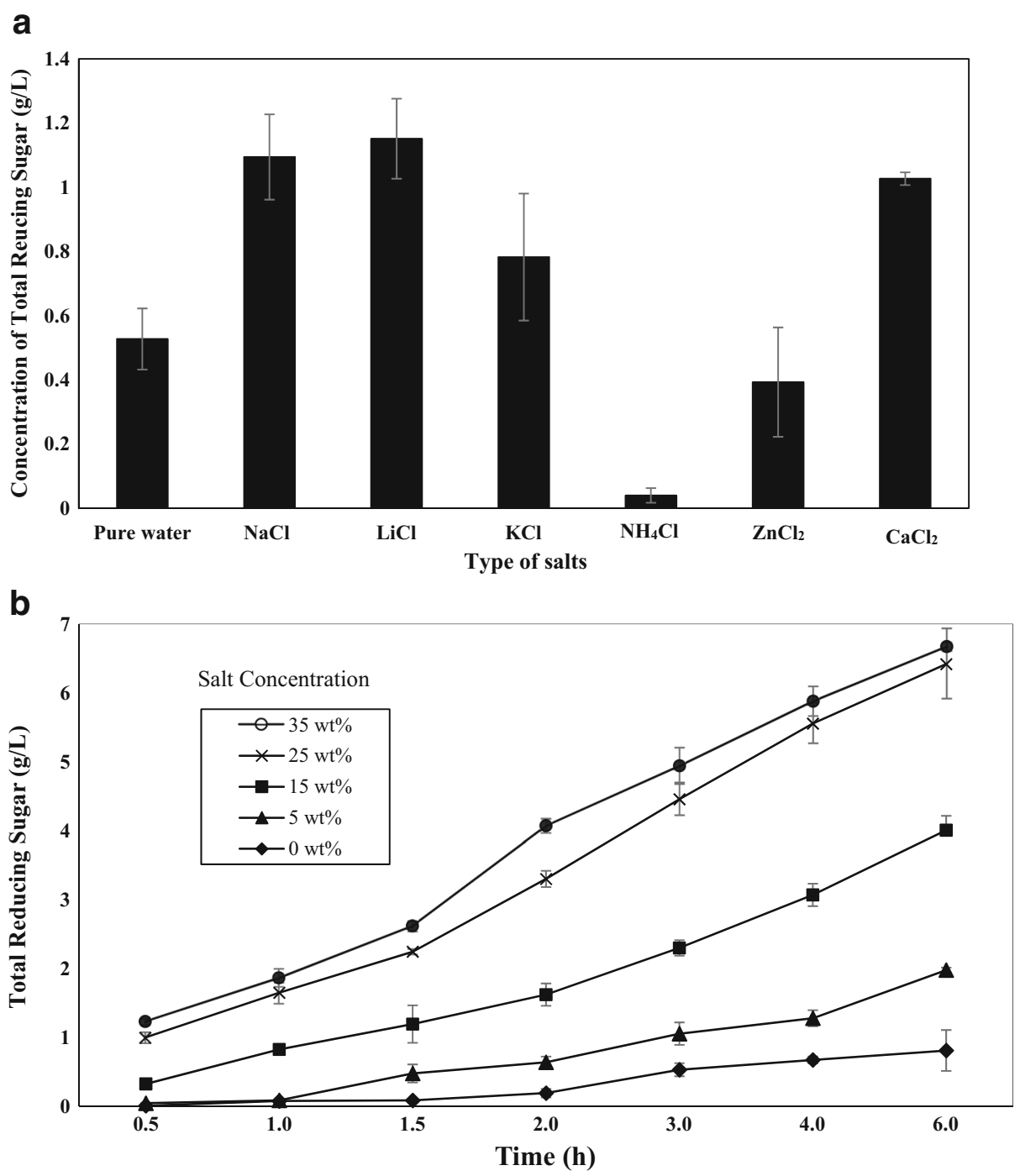

Fig. 1 a Effect of different inorganic salts (10 wt \%), and $\mathbf{b ~} \mathrm{NaCl}$ concentration $(0-35 \mathrm{wt} \%)$ on the depolymerization of SPW (2 wt $\%)$ at $100{ }^{\circ} \mathrm{C}$ (oil bath) in the presence of oxalic acid $(100 \mathrm{mM})$

of SPW (Fig. 2a). This could be attributed to different acid dissociation constants $\left(p K_{a}\right)$ of various dicarboxylic acids: oxalic acid (1.23), maleic acid (1.9), citric acid (3.1), and succinic acid (4.2). Oxalic acid, with the lowest $p K_{a}$ value, produced the most hydronium ions required for the depolymerization of SPW and hence the highest TRS production [30, 31]. The comparatively lower catalytic effect of citric acid than that of oxalic acid concurred with findings reported by vom Stein et al. [32] that citric acid exhibited low catalytic effect on the hydrolysis of Avicel cellulose. Both maleic and citric acids exhibited considerable catalytic effect on the depolymerization of SPW with increased TRS concentrations with reaction time. However, succinic acid was observed to exhibit negligible catalytic effect on the 
depolymerization of SPW. In the case of oxalic acid, the TRS concentration was observed to increase continuously with increasing duration of reaction.

Figure $2 \mathrm{~b}$ shows the effect of oxalic acid and maleic acid concentrations on TRS production from the depolymerization of $2 \mathrm{wt} \%$ of SPW in $25 \mathrm{wt} \% \mathrm{NaCl}$ solution at $100{ }^{\circ} \mathrm{C}$. The production of TRS was negligible at low concentrations of both oxalic acid and maleic acid $(<30 \mathrm{mM})$ but increased readily as their concentrations were increased to more than $30 \mathrm{mM}$. Maximum concentrations of TRS at 5 and $3.5 \mathrm{~g} / \mathrm{L}$ were obtained with oxalic acid and maleic acid at 200 and $400 \mathrm{mM}$, respectively. Oxalic acid was observed to exhibit substantially higher overall catalytic activity than maleic acid which could be due to its comparatively stronger acidic strength: oxalic acid $\left(p K_{a} 1.2\right)$ and maleic acid $\left(p K_{a} 1.9\right)$.
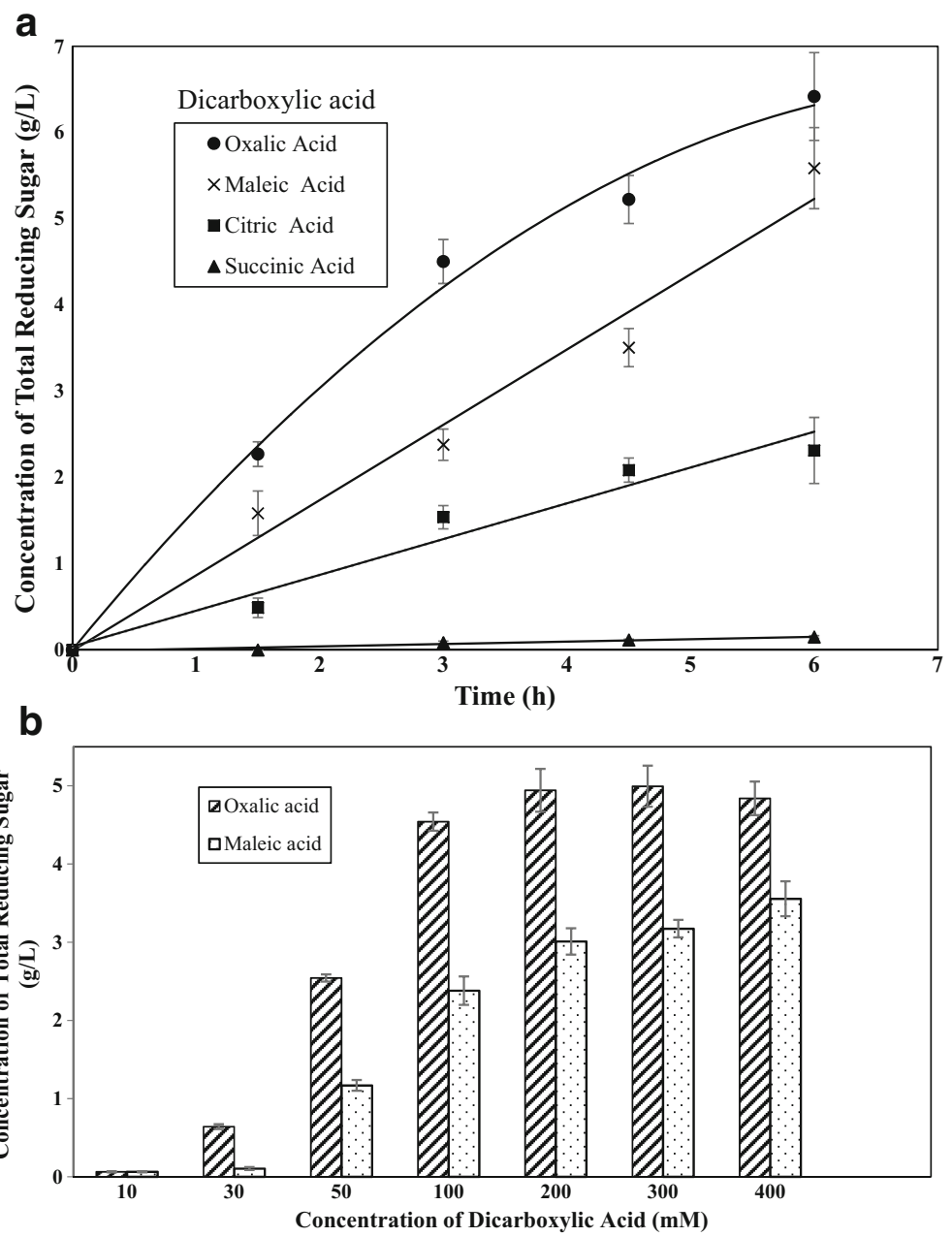

Fig. 2 a Effect of different types of dicarboxylic acid $(100 \mathrm{mM})$, and $\mathbf{b}$ dicarboxylic acid concentrations $(10-$ $400 \mathrm{mM}$ ) on the depolymerization of sago pith waste $(2 \mathrm{wt} \%)$ at $100{ }^{\circ} \mathrm{C}$ (oil bath) in sodium chloride solution $(25 \mathrm{wt} \%)$ 


\section{Effect of Reaction Temperature}

Temperature is one of important factors that influences the depolymerization process of SPW. Figure 3 shows the effect of the temperature on the concentration of TRS produced at various reaction durations in the presence of oxalic acid at two different concentrations. Both 100 and $200 \mathrm{mM}$ of oxalic acid were selected in this study as both concentrations produce quite similar concentrations of TRS (Fig. 2). Oxalic acid of higher concentration resulted in a slightly faster depolymerization rate than that of lower concentration. This result concurred with previous results reported on the effect of dicarboxylic acid concentration [31]. However, the production of TRS via the depolymerization of SPW was observed to decrease rapidly as the reaction temperature was increased beyond 100 and $110{ }^{\circ} \mathrm{C}$ in the presence of 100 and $200 \mathrm{mM}$ of oxalic acid, respectively. Higher reaction temperatures could have promoted the breaking of glycosidic bonds in SPW, thereby resulting in increased formation of TRS. However, higher concentration of oxalic acid (> $200 \mathrm{mM}$ ) could have caused rapid degradation of reducing sugars and, hence, lower TRS concentrations were produced. The optimum conditions for obtaining the highest yield of TRS from the depolymerization of SPW were at reaction temperature of $110{ }^{\circ} \mathrm{C}$, and in the presence of $100 \mathrm{mM}$ oxalic acid as well as $25 \mathrm{wt} \%$ sodium chloride.

\section{Effect of SPW Loading}

The effect of SPW loading $(0.5-8 w / v \%)$ on the depolymerization process is shown in Fig. 4a. Analyses of hydrolysates obtained from different loadings of SPW sample revealed that TRS concentration increased linearly with the loading of SPW at $0.5-8.0 \mathrm{w} / \mathrm{v} \%(1.32-17.23 \mathrm{~g} / \mathrm{L})$. However, the percentage yield of TRS was observed to increase initially from 0.5 to $2 \mathrm{w} / \mathrm{v} \%$ of SPW, but decreased gradually at higher SPW loading (4-8 w/v\%). At lower loading of SPW,

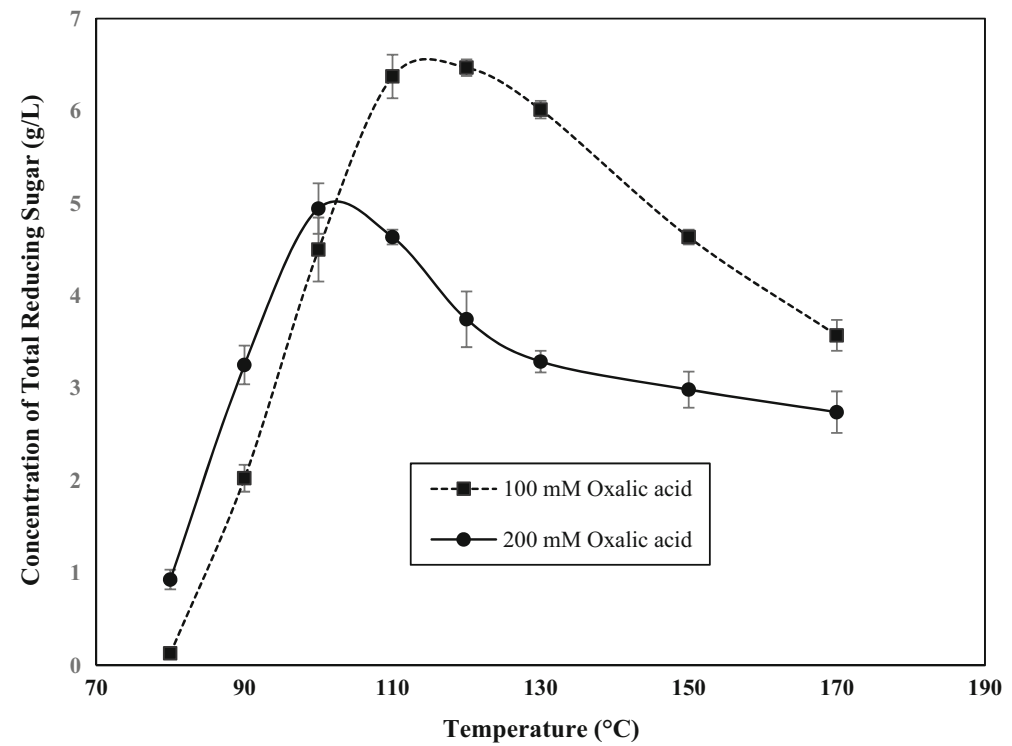

Fig. 3 Effect different reaction temperature on the depolymerization of SPW (2 wt \%) in the presence of 100 or $200 \mathrm{mM}$ oxalic acid, and in sodium chloride solution ( $25 \mathrm{wt} \%)$ for $3 \mathrm{~h}$ 
oxalic acid could effectively cleave the glycosidic bonds in SPW. Nevertheless, the higher viscosity of reaction mixture at higher loading of SPW due to the gelatinization of starch in SPW at $110^{\circ} \mathrm{C}$ could have impeded the hydrolysis process, thereby resulted in lower yield of TRS. Besides, higher loading of SPW used could increase the shielding effect of cellulose fibers which hindered the accessibility of hydronium ions during the depolymerization process.

In order to further enhance the yield of TRS, SPW samples of four different weight percentages were depolymerized sequentially for four depolymerization cycles (Fig. 4b). The hydrolysates were completely withdrawn from the SPW sample after completion of each cycle. Equal volume of $\mathrm{NaCl}$ solution and oxalic acid mixture was added for subsequently depolymerization cycle. The yields of TRS were observed to increase from 71 to 99 and 48 to $79 \%$ after second cycle of depolymerization of SPW samples at loading of 2 and $8 w / v \%$, respectively (Fig. 4b). However, no further increase in the yields of TRS was observed, in particular, for SPW samples with higher loading of 6 and $8 w / v \%$ in the subsequent

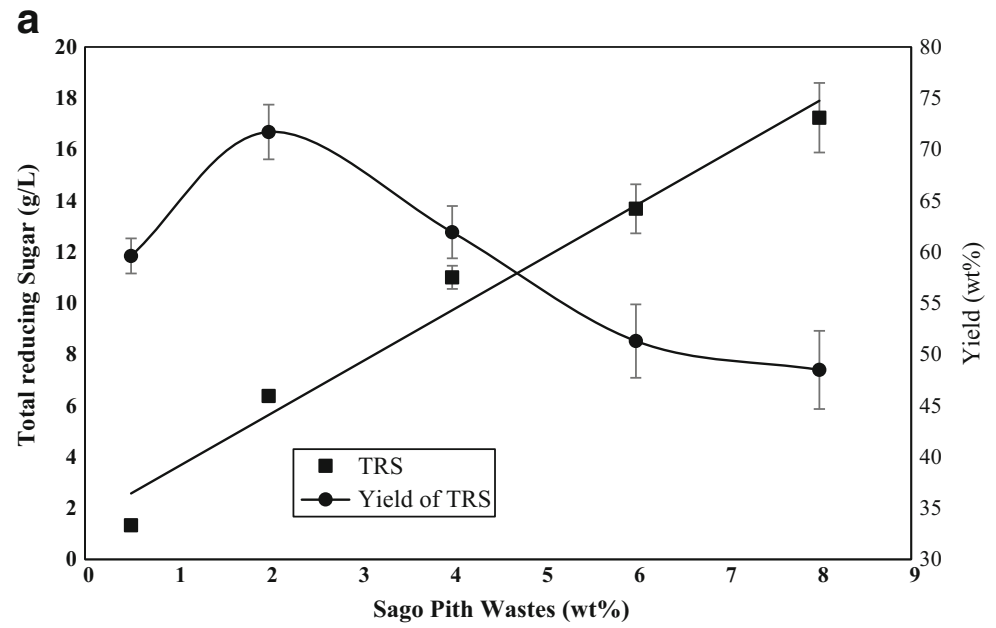

b

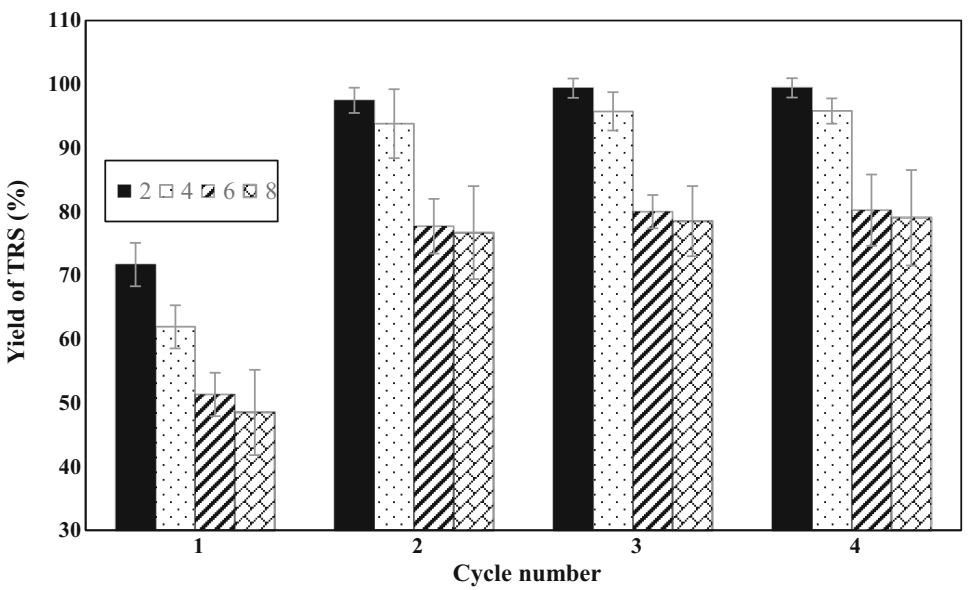

Fig. 4 a Effect of SPW sample loading (0.5-8.0 w/v\%), and b number of depolymerization cycle, on the yield of total reducing sugar at $110{ }^{\circ} \mathrm{C}$ (oil bath) in sodium chloride solution (25 wt \%) and oxalic acid (100 mM) for $3 \mathrm{~h}$ 
depolymerization cycles. This could be attributed to the comparatively lower oxalic acid/ sample loading ratios used which became less effective for depolymerizing the crystalline cellulose structure of the SPW samples during subsequent depolymerization cycles.

\section{Effect of Reaction Time}

Figure 5 shows the effect of reaction time on the yield of TRS and glucose produced in the depolymerization of SPW sample. The concentrations of both TRS and glucose were observed to increase continually during the reaction time between 0 to $4.5 \mathrm{~h}$. Maximum concentrations of TRS and glucose at 9.70 and $8.0 \mathrm{~g} / \mathrm{L}$, respectively, were obtained after depolymerization for $6 \mathrm{~h}$. Analyses using HPLC had revealed that glucose was the main component of hydrolysates obtained from the depolymerization of SPW. The concentration of glucose was observed to increase concomitantly with the concentration of TRS during the initial stage of depolymerization for up to about $3 \mathrm{~h}$ (Fig. 5). The glucose content in TRS produced from the depolymerization of SPW was observed to be as high as $82 \mathrm{w} / v \%$. This result showed that the depolymerization of SPW in $\mathrm{NaCl}$ solution catalyzed by oxalic acid was very selective towards the formation of glucose instead of other reducing sugars such as dextrin, maltose, and maltotriose. Such high yield of glucose produced by the depolymerization of SPW under mild condition showed that SPW can potentially be used as the main feedstock in a biorefinery for biofuels or functional chemical production.

\section{Oxalic Acid Catalysis Versus Enzymatic Depolymerization of SPW}

Table 1 shows a comparison of TRS yields obtained from the depolymerization of SPW samples in this study and those as reported in literatures. In this study, the optimum conditions for the depolymerization of SPW were $2 \mathrm{wt} \%$ sample loading in $25 \mathrm{wt} \%$ of $\mathrm{NaCl}$ solution, and in the presence of $100 \mathrm{mM}$ of oxalic acid at $110^{\circ} \mathrm{C}$ for $3 \mathrm{~h}$ and two sequential reaction cycles. The yield of TRS obtained from SPW in the sequential depolymerization conducted in this study was substantially higher at $97 \%$ as compared to those of other studies. In comparison,

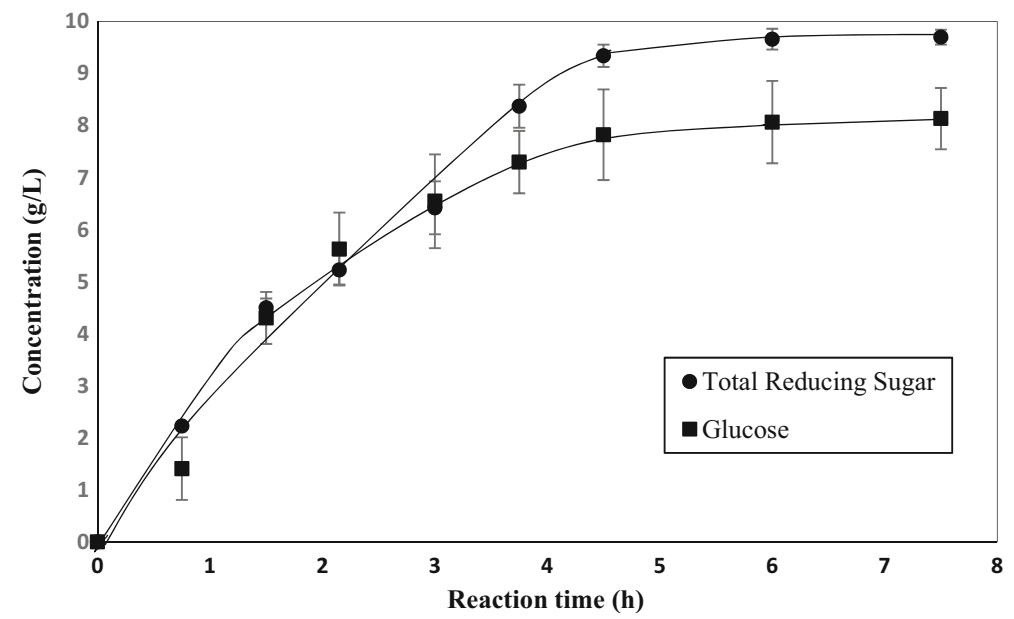

Fig. 5 Effect of reaction time on the TRS and glucose concentrations produced via the depolymerization of SPW $(2 \mathrm{w} / v \%)$ at $110{ }^{\circ} \mathrm{C}$ (oil bath) in sodium chloride (25 wt\%) and oxalic acid (100 mM) 
Table 1 Yields of TRS obtained from depolymerization of sago pith wastes under different conditions

\begin{tabular}{llll}
\hline Sample loading $(w / v \%)$ & Depolymerization method & Yield of TRS $(\%)$ & References \\
\hline 2.0 & Oxalic acid in NaCl solution $(1$ cycle) & 71.7 & This study \\
2.0 & $\begin{array}{l}\text { Oxalic acid in NaCl solution } \\
\text { (after 2 sequential cycles) }\end{array}$ & 97.1 & This study \\
8.0 & Oxalic acid in NaCl solution & 48.5 & This study \\
5.0 & Enzymatic hydrolysis & 73.0 & Linggang et al. [8] \\
7.0 & Enzymatic hydrolysis & 40.0 & Awg-Adeni et al. [7] \\
5.0 & Enzymatic hydrolysis & 71.0 & Jenol et al. [4] \\
\hline
\end{tabular}

the TRS yield (40\%) obtained from enzymatic hydrolysis of SPW was lower than that of oxalic acid-catalyzed depolymerization in $\mathrm{NaCl}$ solution (48.5\%) at high SPW loading of 7.0 and $8.0 \mathrm{w} / \mathrm{v} \%$, respectively. Oxalic acid-catalyzed depolymerization exhibited a substantially higher depolymerization rate requiring only $3-6 \mathrm{~h}$ as compared with that of enzymatic depolymerization which required 2-3 days. Besides, the use of oxalic acid as catalyst in the depolymerization of SPW would incur substantially lower cost than that of enzymes used in enzymatic depolymerization. These findings clearly indicated the feasibility of the oxalic acidcatalyzed depolymerization of SPW in $\mathrm{NaCl}$ solution for cost-effective production of TRS.

\section{Conclusion}

The present study demonstrates a facile depolymerization process for converting sago pith waste (SPW) to fermentable sugars (TRS) in the presence of oxalic acid as the catalyst in $\mathrm{NaCl}$ solution under mild conditions. The yields of TRS were dependent on the concentration of catalyst, reaction temperature, and number of depolymerization cycle, as well as the reaction time. Under optimized depolymerization conditions, a maximum TRS yield of $97 \%$ was achieved with glucose constituted more than $80 \%$ of TRS produced. TRS derived from sago pith waste could therefore be potential feedstock for the production of biofuels and bio-based chemicals.

Acknowledgements The authors wish to acknowledge the financial support rendered by the Malaysian Ministry of Higher Education (MOHE) via the award of fundamental research grants (Grant No. FRGS/ST01(01)/967/2013(08) and F07/FRGS/1495/2016), as well as research management and support provided by the Research Innovation and Management Center (RIMC), Universiti Malaysia Sarawak.

\section{Compliance with Ethical Standards}

Conflict of Interest The authors declare that they have no conflicts of interest.

\section{References}

1. Limayem, A., \& Ricke, S. C. (2012). Lignocellulosic biomass for bioethanol production: current perspectives, potential issues and future prospects. Progress in Energy and Combustion Science, 38, 449-467. 
2. Herbert, G. J., \& Krishnan, A. U. (2016). Quantifying environmental performance of biomass energy. Renewable Sustainable Energy Reviews, 59, 292-308.

3. Cavka, A., Guo, X., Tang, S. J., Winestrand, S., Jönsson, L. J., \& Hong, F. (2013). Production of bacterial cellulose and enzyme from waste fiber sludge. Biotechnology for Biofuels, 6, 1-7.

4. Jenol, M. A., Ibrahim, M. F., Yee, P. L., Salleh, M. M., \& Abd-Aziz, S. (2013). Sago biomass as a sustainable source for biohydrogen production by Clostridium butyricum A1. BioResources, 9, 1007-1026.

5. Thangavelu, S. K., Ahmed, A. S., \& Ani, F. N. (2014). Bioethanol production from sago pith waste using microwave hydrothermal hydrolysis accelerated by carbon dioxide. Apply Energy, 128, 277-283.

6. Lai, J. C., Rahman, W. A. W. A., \& Toh, W. Y. (2013). Characterisation of sago pith waste and its composites. Industrial Crop Production, 45, 319-326.

7. Awg-Adeni, D. S., Abd-Aziz, S., Bujang, K., \& Hassan, M. A. (2010). Bioconversion of sago residue into value added products. African Journal of Biotechnology, 9, 2016-2021.

8. Linggang, S., Phang, L. Y., Wasoh, M. H., \& Abd-Aziz, S. (2012). Sago pith residue as an alternative cheap substrate for fermentable sugars production. Apply Biochemistry Biotechnology, 167, 122-131.

9. Demirbas, A. (2011). Competitive liquid biofuels from biomass. Apply Energy, 88, 17-28.

10. Zhu, S., Wu, Y., Yu, Z., Zhang, X., Wang, C., Yu, F., \& Jin, S. (2006). Production of ethanol from microwave-assisted alkali pretreated wheat straw. Process Biochemistry, 41, 869-873.

11. Alvira, P., Tomás-Pejó, E., Ballesteros, M., \& Negro, M. J. (2010). Pretreatment technologies for an efficient bioethanol production process based on enzymatic hydrolysis: a review. Bioresource Technology, 101, 4851-4861.

12. Van Dyk, J. S., \& Pletschke, B. I. (2012). A review of lignocellulose bioconversion using enzymatic hydrolysis and synergistic cooperation between enzymes-factors affecting enzymes, conversion and synergy. Biotechnology Advance, 30, 1458-1480.

13. Zaldivar, J., Nielsen, J., \& Olsson, L. (2001). Fuel ethanol production from lignocellulose: a challenge for metabolic engineering and process integration. Apply Microbiology Biotechnology, 56, 17-34.

14. Fan, J., Zhu, Z., Budarin, V., Gronnow, M., Gomez, L. D., Macquarrie, D., \& Clark, J. (2013). Microwaveenhanced formation of glucose from cellulosic waste. Chemical Engineering Processing: Process Intensification, 71, 37-42.

15. Sarkar, N., Ghosh, S. K., Bannerjee, S., \& Aikat, K. (2012). Bioethanol production from agricultural wastes: an overview. Renewable Energy, 37, 19-27.

16. Ross, A. B., Biller, P., Kubacki, M. L., Li, H., Lea-Langton, A., \& Jones, J. M. (2010). Hydrothermal processing of microalgae using alkali and organic acids. Fuel, 89, 2234-2243.

17. Sakaki, T., Shibata, M., Sumi, T., \& Yasuda, S. (2002). Saccharification of cellulose using a hot-compressed water-flow reactor. Industrial Engineering Chemistry Research, 41, 661-665.

18. Kang, K. E., Park, D. H., \& Jeong, G. T. (2013). Effects of inorganic salts on pretreatment of Miscanthus straw. Bioresource Technology, 132, 160-165.

19. Xing, R., Liu, S., Yu, H., Guo, Z., Wang, P., Li, C., \& Li, P. (2005). Salt-assisted acid hydrolysis of chitosan to oligomers under microwave irradiation. Carbohydrate Resource, 340, 2150-2153.

20. Liu, L., Sun, J., Cai, C., Wang, S., Pei, H., \& Zhang, J. (2009). Corn stover pretreatment by inorganic salts and its effects on hemicellulose and cellulose degradation. Bioresource Technology, 100, 5865-5871.

21. Wongsiriwan, U., Noda, Y., Song, C., Prasassarakich, P., \& Yeboah, Y. (2010). Lignocellulosic biomass conversion by sequential combination of organic acid and base treatments. Energy and Fuels, 24, 32323238 .

22. Vanoye, L., Fanselow, M., Holbrey, J. D., Atkins, M. P., \& Seddon, K. R. (2009). Kinetic model for the hydrolysis of lignocellulosic biomass in the ionic liquid, 1-ethyl-3-methyl-imidazolium chloride. Green Chemistry, 11, 390-396.

23. Kootstra, A. M. J., Beeftink, H. H., Scott, E. L., \& Sanders, J. P. (2009). Comparison of dilute mineral and organic acid pretreatment for enzymatic hydrolysis of wheat straw. Biochemical Engineering Journal, 46, 126-131.

24. Lee, J. W., Rodrigues, R. C., \& Jeffries, T. W. (2009). Simultaneous saccharification and ethanol fermentation of oxalic acid pretreated corncob assessed with response surface methodology. Bioresource Technology, 100, 6307-6311.

25. Mosier, N. S., Sarikaya, A., Ladisch, C. M., \& Ladisch, M. R. (2001). Characterization of dicarboxylic acids for cellulose hydrolysis. Biotechnology Progress, 17, 474-480.

26. Sluiter, A., \& Sluiter, J. (2008). Determination of starch in solid biomass samples by HPLC: Laboratory Analytical Procedure (LAP): Issue Date, 07/17/2005. National Renewable Energy Laboratory.

27. Sluiter, A., Hames, B., Ruiz, R., Scarlata, C., Sluiter, J., Templeton, D., \& Crocker, D. (2008). Determination of structural carbohydrates and lignin in biomass. In Laboratory Analytic Procedure (LAP) of the National Renewable Energy Laboratory (NREL). Colorado: USA Google Scholar. 
28. Liu, F., Kamat, R. K., Noshadi, I., Peck, D., Parnas, R. S., Zheng, A., \& Lin, Y. (2013). Depolymerization of crystalline cellulose catalyzed by acidic ionic liquids grafted onto sponge-like nanoporous polymers. Chemical Communication, 49, 8456-8458.

29. Vincent, M., Senawi, B. R. A., Esut, E., Nor, N. M., \& Adeni, D. S. A. (2015). Sequential saccharification and simultaneous fermentation (SSSF) of sago hampas for the production of bioethanol. Sains Malaysian, 44, 899-904.

30. Faria, P. C. C., Órfão, J. J. M., \& Pereira, M. F. R. (2008). Activated carbon catalytic ozonation of oxamic and oxalic acids. Applied Catalysis B: Environmental, 79, 237-243.

31. Mosier, N. S., Ladisch, C. M., \& Ladisch, M. R. (2002). Characterization of acid catalytic domains for cellulose hydrolysis and glucose degradation. Biotechnology and Bioengineering, 79, 610-618.

32. vom Stein, T., Grande, P., Sibilla, F., Commandeur, U., Fischer, R., Leitner, W., \& de María, P. D. (2010). Salt-assisted organic-acid-catalyzed depolymerization of cellulose. Green Chemistry, 12, 1844-1849. 